HEAD AND NECK

\title{
Spinal accessory nerve preservation in modified neck dissections: surgical and functional outcomes
}

\author{
Preservazione del nervo accessorio spinale nelle dissezioni del collo: \\ outcomes chirurgici e funzionali
}

\author{
V. POPOVSKI ${ }^{1}$, A. BENEDETTI ${ }^{1}$, D. POPOVIC-MONEVSKA ${ }^{1}$, A. GRCEV ${ }^{1}$, A. STAMATOSKI ${ }^{1}$, J. ZHIVADINOVIK² \\ ${ }^{1}$ Clinic for Maxillofacial Surgery, St Cyril and Methodius University, Skopje, R. Macedonia; ${ }^{2}$ Institute of Anatomy, \\ Medical Faculty, St Cyril and Methodius University, Skopje, R. Macedonia
}

\begin{abstract}
SUMMARY
The spinal accessory nerve (SAN) or XI cranial nerve is frequently encountered during neck surgery, and as such is at risk of iatrogenic injury, resulting in "shoulder syndrome". Modified neck dissection (MND) with preservation of the SAN is based on desire to minimise the functional deformity associated with section of the eleventh nerve. The aim of this study was to analyse the intra-operative variations of the spinal accessory nerve pathway and to evaluate shoulder dysfunction postoperatively. The cross-sectional demonstration analysis was created through the medical records retrospectively of 165 consecutive patients who underwent neck dissections at our institution in the past 5 years with attention to ultrasound and MRI preoperative findings, type of neck dissection, type of identification and dissection of SAN, postoperative morbidity and survival rate. The safest identification of SAN is in the posterior neck triangle where it may be recognised exiting from the posterior border of the sternocleidomastoid muscle (SCM) at Erb's point. For exact preoperative planning, ultrasound and MRI are superior to determine the position of the eleventh nerve. The mean distance between the greater auricular point and the SAN was $0.90 \mathrm{~cm}$. Average length of the trunk from Erb's point until the penetration in the trapezius muscle was around $5.1 \mathrm{~cm}$, ranging from 4.8 to $5.4 \mathrm{~cm}$. The diversity in the course from the posterior border of the SCM and posterior neck triangle was confirmed in 9 cases (15\%), predominantly at the level of entering the posterior neck triangle. The frequency of postoperative morbidity of SAN was $46.7 \%$ for radical neck dissections, $42.5 \%$ for selective neck dissections and 25\% for MND. For each separate type of dissection, different subtypes were included. Identification of the SAN over established landmarks is unconditionally reliant on the exact preoperative mapping of the nerve with imaging diagnostics. MND has similar regional control rates to more comprehensive operations in appropriately selected patients and significantly reduces the risk of functional disability.
\end{abstract}

KEY WORDS: Posterior neck triangle $\bullet$ Spinal accessory nerve $\bullet$ Neck metastases $\bullet$ Modified neck dissection $\bullet$ Shoulder function

\section{RIASSUNTO}

Durante la chirurgia del collo, ci si imbatte frequentemente nel nervo accessorio spinale (SAN) o XI nervo cranico che, pertanto, è a rischio di lesione iatrogena con conseguente "sindrome della spalla". La dissezione del collo modificata con preservazione del SAN è basata sull'intento di minimizzare le deformità funzionali causate dalla sezione dell'undicesimo nervo. L'obiettivo di questo studio è quello di descrivere le varianti intraoperatorie del nervo accessorio spinale e valutare la disfunzione della spalla nel postoperatorio. Lo studio osservazionale trasversale è stato creato analizzando retrospettivamente 165 pazienti consecutivi che sono stati sottoposti a dissezione del collo presso il nostro istituto negli ultimi 5 anni, ponendo particolare attenzione ai reperti preoperatori derivanti da ecografia e risonanza magnetica, al tipo di dissezione del collo, al tipo di identificazione e dissezione del SAN, ai dati postoperatori di morbilità e sopravvivenza. La più sicura identificazione del SAN avviene nel triangolo posteriore del collo, dove potrebbe essere riconosciuto in quanto emerge dal margine posteriore del muscolo sternocleidomastoideo, a livello del cosiddetto punto di Erb. Per un corretto planning preoperatorio, ecografia e risonanza magnetica sono superiori nel determinare l'esatta posizione dell'undicesimo nervo cranico. La distanza media tra il nervo grande auricolare e il SAN è stata di circa 0,90 cm. La lunghezza media del tronco nervoso dal punto di Erb fino al punto in cui esso penetra nel muscolo trapezio è stata di circa 5,1 cm, con un range da 4,8 e 5,4 cm. La diversità nel decorso dal bordo posteriore dello muscolo sternocleidomastoideo attraverso il triangolo posteriore del collo è stata riscontrata in 9 casi (15\%), soprattutto a livello dell'ingresso nel triangolo posteriore del collo. La frequenza di lesione postoperatoria del SAN è stata del 46,7\% per le dissezioni radicali del collo, del 42,5\% per le dissezioni selettive, e del 25\% per le dissezioni modificate. Per ciascun tipo di svuotamento, sono stati inclusi differenti sottotipi. L'identificazione del SAN, step fondamentale nella chirurgia del collo, è assolutamente dipendente da un corretto studio preoperatorio attraverso la diagnostica per immagini. La dissezione del collo modificata ha percentuali di controllo regionale simili a quelle di operazioni più demolitive in pazienti accuratamente selezionati, e riduce significativamente il rischio di disturbi funzionali.

PAROLE CHIAVE: Triangolo posteriore del collo $\bullet$ Nervo accessorio spinale $・$ Metastasi cervicali $\bullet$ Dissezione del collo modificata $\bullet$ Funzione della spalla 


\section{Introduction}

While radical neck dissection (RND) had a principal role in the treatment of cervical neck metastasis for many years, the oncological requirement for RND became disputable upon the definition of "shoulder syndrome" in the second half of the last century ${ }^{12}$. Consequently, modified radical neck dissection (mRND) with preservation of the spinal accessory nerve (SAN) and removal of lymphatic tissues with similar oncological results was described. However, identification of the spinal accessory nerve even in the correct anatomical position is not always easy during different types of neck dissections. The surgical anatomy of the spinal accessory nerve has been properly acknowledged in the literature with evidence of significant variations ${ }^{1-4}$. The eleventh cranial nerve topography consists of two parts, a cranial part and a main cervical part. The nerve descends in the neck through jugular foramen and near the jugular vein exits in the posterior neck triangle and supplies the sternocleidomastoid and trapezius muscles. These muscles have the functions of: elevation of the shoulder by the trapezius, rotation and tilting of the head toward and away from the side of the contracting sternocleidomastoid muscle and flexion of the neck by both sternocleidomastoid muscles. This cervical part is associated by motor or sensory contributions from the upper cervical nerves. These functions are decreased or absent of weakness or paralysis. When the lesion is nuclear or infranuclear, there is associated muscle atrophy and fasciculations ${ }^{5-7}$.

On the other hand, neck dissection is a principal technique for diagnosis (staging) and treatment of cervical lymph node metastasis in patients with head and neck cancer. In modified neck dissections when indications are raised, a very important part is preservation of the spinal accessory nerve, together with internal jugular vein and sternocleidomastoid muscle $^{8-10}$. The pain and dysfunction associated with loss of innervation on spinal accessory nerve has motivated surgeons to modify the classic neck dissection. The modified neck dissection with preservation of the spinal accessory nerve is based on desire to minimise the functional deformity associated with section of that nerve, combined with the recognition that in many situations the nerve intimately involved in the neck disease and its preservation does not compromise the oncological effectiveness of the more limited procedure ${ }^{411-14}$.

Since the introduction of functional neck dissection, various modifications have been made to reduce the adverse effects of radical neck dissection and have contributed to improving the quality of life and preventing permanent sequelae and medico-legal actions following neck dissection ${ }^{4}$. Proficient knowledge of posterior neck anatomy is crucial to avoid its accidental injury during selective or modified neck dissection in almost any extensive surgery of the posterior neck. Reasonable speed and safety in identifying and preserving important anatomical structures are of fundamental importance, and for this type of neck dissection special attention must be paid to refined identification of the spinal accessory nerve. The aim of this study was to analyse the intra-operative variations of the spinal accessory nerve pathway and to evaluate shoulder dysfunction postoperatively.

\section{Materials and methods}

A comparative, prospective study of surgical alterations of the spinal accessory nerve and trapezius muscle function of patients who underwent distinctive neck surgery was performed. This study was done not only to document the indispensability of the trapezius muscle to shoulderstrap stability, but also to clarify the role of eleventh cranial nerve preservation. The cross-sectional demonstration analysis was created on clinical material from the Clinic for Maxillofacial Surgery in Skopje, where in the last five-year period, unilateral neck dissections were performed in 165 patients, of whom 59 were treated with radical neck dissection, 20 with modified neck dissection and in 86 cases with adequate type of selective neck dissection. Neck dissection with a curative intent was done in 80 patients with squamous cell carcinoma of the upper aerodigestive tract (naso- and oro-pharynx), in 26 patients with skin squamous cell carcinoma, 17 with salivary gland carcinoma, 11 with malignant melanoma and 31 with hidden primary.

We evaluated clinical records for this study in 20 patients with modified neck dissection (type I, II, III) and 40 patients with selective neck dissections (supra-omohyoid, lateral, posterolateral, anterior compartment), comparing preoperative diagnostic work-up, intraoperative findings and relationship of the dissected and preserved eleventh nerve with tumour masses and postoperative complications. T1weighted high-resolution isotropic volume examination for the preoperative assessment of head and neck cancer, by comparison with spin-echo, T1-weighted sequences and the pathology specimen. Bland-Altman plots to assess measurement agreement, Shoulder Disability Questionnaire (SDQ), and Constant-Murley Shoulder Score were used to detect differences between the normal and abnormal sides.

In selected cases, an intraoperative mapping study was done to obtain the exact anatomical data by drawing the exposed accessory nerve in life size during the modified neck dissection. All measurements were made at the end of the procedure by using a Vernier Caliper with $1 / 64$ " in classic anatomic position of the supine body with turned the patient's head about $45^{\circ}$. After the completeness of lymph node and metastases removal from the posterior neck triangle, evaluation was performed over extensive exposure of the spinal accessory nerve. Towards the end of the dissection, the correct location of the nerve was corroborated by enlarging the exposure to confirm the position and integrity of the preserved nerve.

Clinical, electrophysiological and neurologic evaluations of the trapezius and sternocleidomastoid muscles (fibril- 
lation and positive sharp waves) were performed at 3 months postoperatively for $20 \mathrm{mRND}$ and 40 SND patients, and 6 months postoperatively only for $20 \mathrm{mRND}$ patients. Stimulus intensity and duration were increased until the maximal amplitude level was achieved. Latency was defined as the time from the application of stimulus to the initial negative deflection of the amplitude. Statistical analysis was performed using IBM SPSS statistics ver. 20. $\mathrm{P}$ values lower than 0.05 were considered significant.

\section{Results}

Intraoperatively we found significant variances in the positioning of the spinal accessory nerve. Particular attention was paid to identification of spinal accessory nerve positioning and its relationship with the internal jugular vein. Our findings confirmed that the spinal accessory nerve almost always crosses the internal jugular vein anteriorly in the upper neck, with exclusion in 4 cases $(6.7 \%)$, with posterior crossing at the level of posterior belly of the digastric muscle and one case with rare anomaly where accessory nerve passing through the fenestrated internal jugular vein was observed. In 20 cases we measured the distance from the jugular foramen (skull base) to crossing of internal jugular vein with a mean value of $2.34 \mathrm{~cm}$ (ranging from 2.27 to $2.43 \mathrm{~cm}$ ) (Fig.1).

The diversity in the course from the posterior border of the sternocleidomastoid muscle and posterior neck triangle were confirmed in 9 cases $(15 \%)$, predominantly at the level of entering the posterior neck triangle. The hypoplastic nerve was apparent in $8.3 \%$ (5 cases), generally after removal of neck masses with greater proportions. Hyperplastic nerve was evident in only $3.3 \%$ ( 2 cases). In

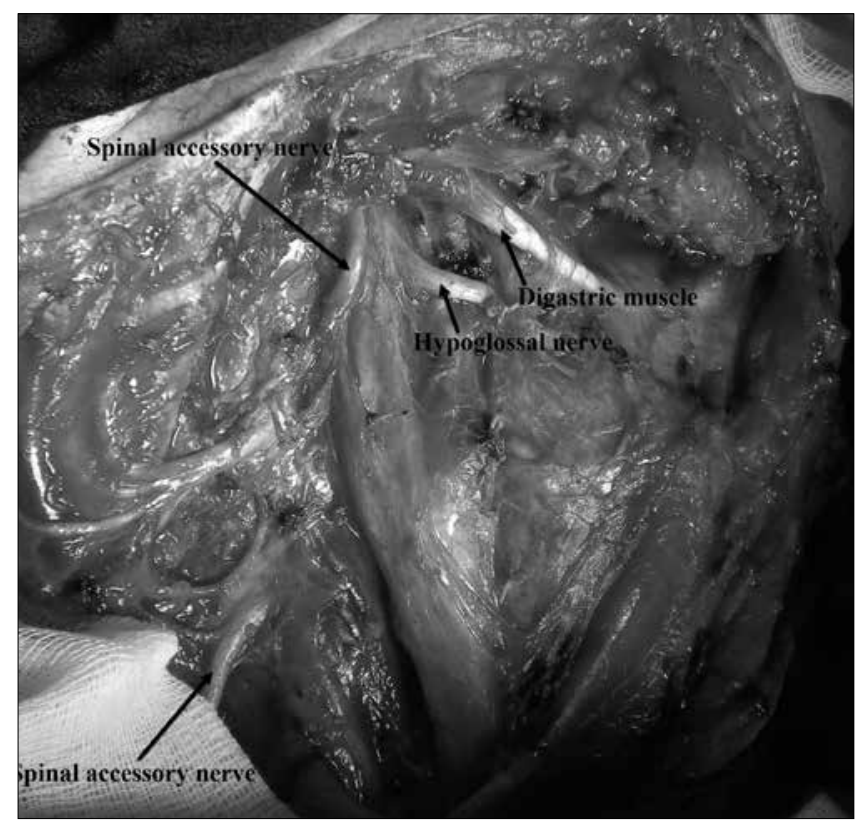

Fig. 1. Identification of spinal accessory nerve in radical neck dissection.

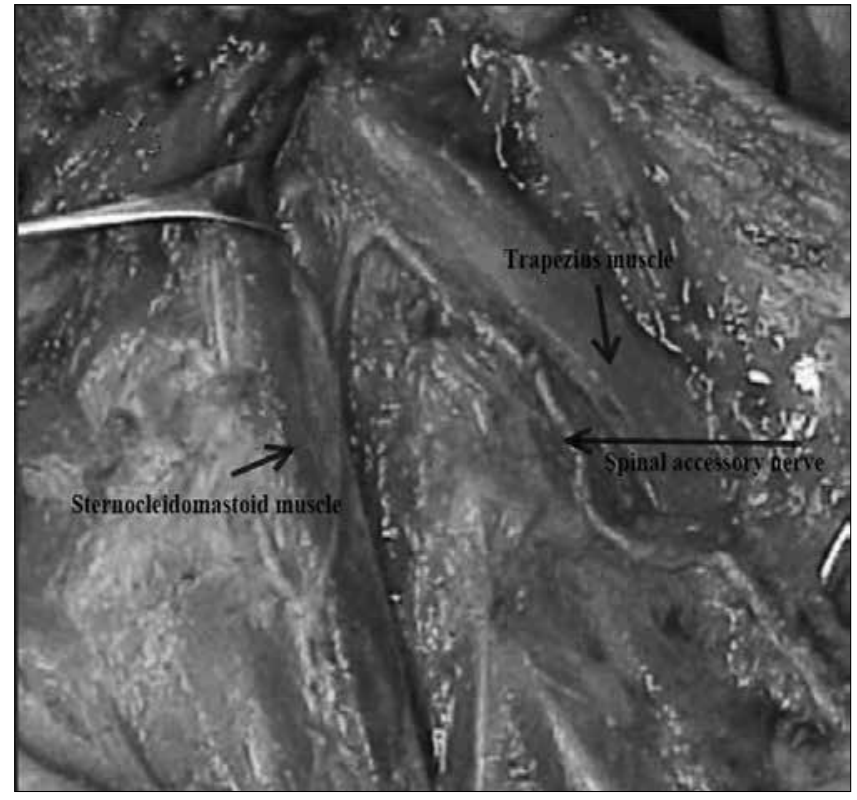

Fig. 2. Modified neck dissection with preserved spinal accessory nerve.

almost every case we found that the spinal accessory nerve had a typical coiled appearance in its course through the posterior cervical triangle of the neck (Fig. 2).

The mean distance between the greater auricular point and the spinal accessory nerve was $0.90 \mathrm{~cm}$. Average length of the trunk from Erb's point until the penetration in the trapezius muscle was around $5.1 \mathrm{~cm}$, ranging from 4.8 to $5.4 \mathrm{~cm}$. The most significant elongation was found in cases after meticolous preparation of spinal accessory nerve - usually after complete removal of neck metastases at levels III - V. There were 4-8 lymph nodes in the spinal accessory nerve chain (Fig. 3).

Measurements of abduction and electromyographic measurements (monopolar needle electrode) of the study group (modified radical neck dissection) in 3 and 6 months postoperatively were found to be superior to those of the control group (selective neck dissection), although the difference between groups was not significant (Table I) Damage to the motor unit averagely recorded at ranges between $320-540 \mathrm{mV}$. The mean number of dissected lymph nodes was significantly higher in the study group than in the control group. The frequency of postoperative morbidity of the spinal accessory nerve was the highest in radical neck dissections $(46.7 \%)$ in 28 cases. There was a reduced function in 17 cases with selective neck dissection $(42.5 \%)$ comparing to preoperative values, while shoulder drop and scapular winging was confirmed in only 5 cases $(25 \%)$ of modified neck dissection.

The most significant was correlation after radical neck dissection and modified neck dissection including levels IIb and V (Fig. 4). Statistical significance was obtained between shoulder pain score and EMG fibrillation or positive sharp wave score $(\mathrm{p}<0.05)$. The Shoulder Disability 
Table I. Comparison of EMG latency values in modified radical neck dissection (mRND) and selective neck dissection (SND) on the operated side (3 months postoperative).

\begin{tabular}{lccccc} 
Accessory nerve & mRND & $\mathbf{n}$ & SND & n & P \\
Lower trapezius (mean \pm SD) & $7.34 \pm 2.17$ & 5 & $8.81 \pm 1.82$ & 8 & 0.257 \\
Middle trapezius & $5.75 \pm 3.25$ & 6 & $5.32 \pm 1.46$ & 9 & 0.481 \\
Upper trapezius & $4.27 \pm 1.36$ & 6 & $4.29 \pm 1.02$ & 11 & 0.429 \\
Pin, trapezius & $6.09 \pm 3.57$ & 3 & $5.24 \pm 4.3$ & 12 & 0.615 \\
\hline
\end{tabular}

${ }^{*} n-$ number of patients

$P<0.05$

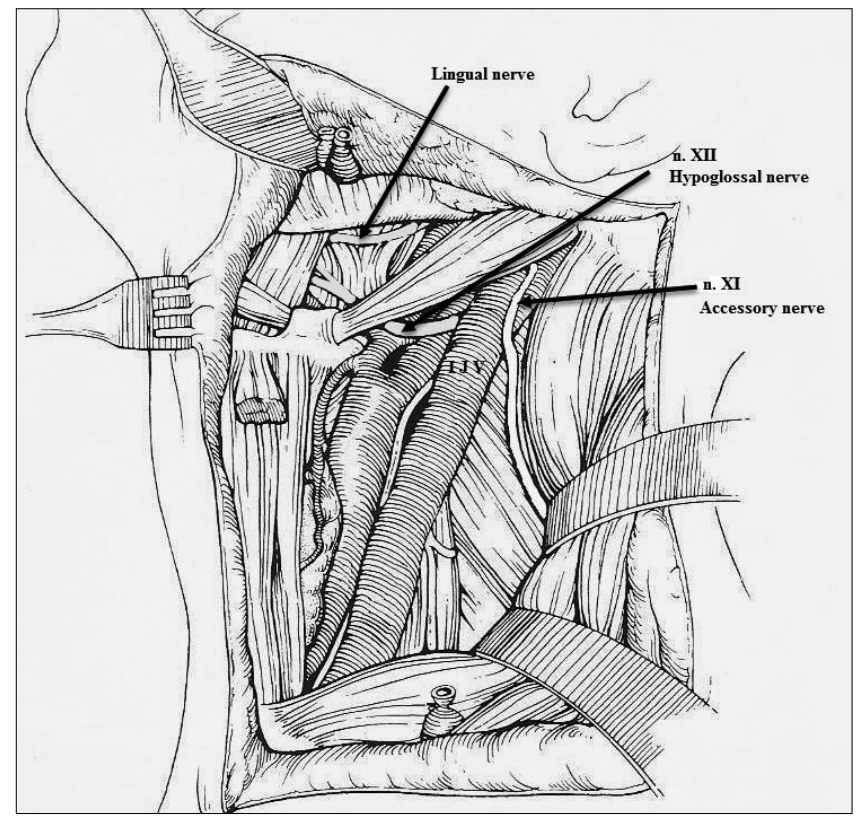

Fig. 3. Cranial nerve XI crossing with internal jugular vein in functional neck dissection (schematic appearance).

Questionnaire score was significantly lower in the spinal accessory nerve preservation group compared to the radical neck dissection group and comparison of active shoulder joint motion ranges on the operated with mRND and the control sides revealed lower EMG discrepancies on operated (abnormal) and control (normal) side (Table II). Visual Analog Scale (VAS) was also used, and $28 \%$ of the patients had no pain.

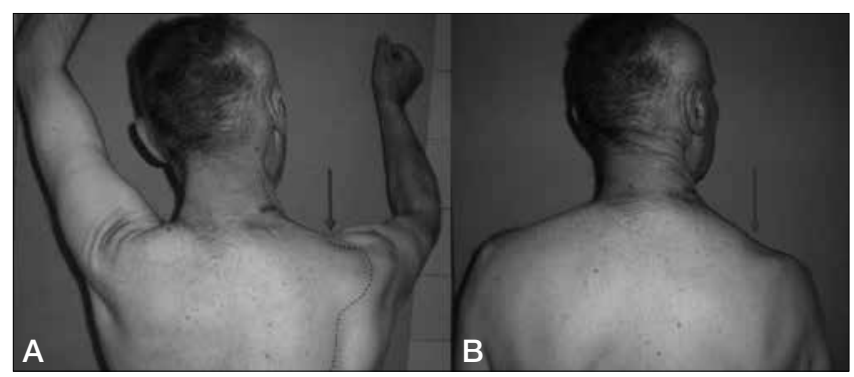

Fig. 4. a. Trapezius muscle disability - right shoulder dropped after radical neck dissection of malignant melanoma; $b$. Dysfunction of the right shoulder - accessory nerve resected.
The arm abduction test was with score of 4.3 in properly treated cases with preservation of SAN.

Five patients with history of adhesive capsulitis were enrolled who had higher $E M G$ ratios of the upper trapezius to lower trapezius during arm elevation.

Patients who underwent supraomohyoid selective neck dissection that involved minimal dissection of the spinal accessory nerve had minimal loss of shoulder function and usually, normal electromyograms in 3 months that documented less injury to the spinal accessory nerve. Again, these patients had improvement with the time. No patient had recurrence of neck disease during at least 3, 6 and 12 months of follow up.

\section{Discussion}

The main therapeutic dilemma for the therapy of metastatic carcinoma from head and neck malignancy remains the choice of the type of neck dissection. The probability of metastases to the neck from various sites in the upper aerodigestive tract has been outlined ${ }^{10}{ }^{15}$, so there are data from much of the literature on the technique and indications for functional modifications of the classical radical neck dissection. Conley and Schuller ${ }^{10}$ confirmed a large percentage of metastases (42\%) in close proximity to the spinal accessory nerve where it comes to lie near the internal jugular vein. Ballantyne, Shah and Bocca's group ${ }^{10}$ gave strong support to MRND emphasising that in many situations the spinal accessory nerve is not intimately involved in neck disease and its preservation does not comprise the oncologic effectiveness of the more limited procedure. These and other investigations have designated the introduction of modified neck dissections.

Beneficial surgical intervention in case of posterior neck metastases depends on suitable exposure and preservation of the spinal accessory nerve. This induces a consistent understanding of the anatomy of the posterior neck triangle for performing surgery safely, including the sufficient knowledge of extracranial anatomy of spinal accessory nerve variations ${ }^{11} 16-18$.

Patten and Hillei ${ }^{19}$ indicated that adhesive capsulitis is a principal component of XI nerve syndrome that can significantly compound the morbidity of a neck dissection even when the accessory nerve recovers. 
Table II. Comparison of active shoulder joint motion ranges on the operated with mRND and the control sides.

\begin{tabular}{lcccc} 
Shoulder function & Operated (mean \pm SD) & Control (mean \pm SD) & n & P \\
Flexion & $130.7 \pm 24.5$ & $143 \pm 15.6$ & 20 & $<0.002$ \\
Abduction & $128.3 \pm 27.3$ & $144.6 \pm 14.3$ & 20 & $<0.002$ \\
Internal rotation & $71.2 \pm 13.1$ & $72.5 \pm 11$ & 20 & 0.477 \\
External rotation & $64.5 \pm 11.3$ & $68.7 \pm 11.9$ & 20 & 0.019 \\
\hline
\end{tabular}

Our findings support results in the literature that the spinal accessory nerve is located anterior to the internal jugular vein in the majority of the cases, although it is imperative for the surgeon to be mindful to anatomic variability and possible posterior crossing of the internal jugular vein by the spinal accessory nerve in the neck to avoid injury to the internal jugular vein during the dissection of the nerve. Since the great auricular nerve (Erb's point) represents a constantly identifiable landmark, it allows simple and reliable identification of the course of the spinal accessory nerve. Across the posterior triangle, the nerve was running superficially with either straight $(78 \%)$ or coiled $(22 \%)$ pathway. The accessory nerve and the phrenic nerve were similar in terms of anatomic evidence and number of motor nerve fibres. On ultrasound evaluation, the accessory nerve exited the posterior border of sternocleidomastoid at a mean of $6.5(5.0-8.5) \mathrm{cm}$ below the mastoid process and penetrated the anterior border of trapezius $5.5(3.0-7.0) \mathrm{cm}$ above the clavicle with mean caliber of $0.75 \pm 0.10 \mathrm{~mm}$.

The most common complication of neck dissection is shoulder pain and dysfunction due to manipulation of the spinal accessory nerve, resulting in trapezius muscle atrophy mainly in procedures involving the posterior neck triangle ${ }^{18}$.

Lee et al. ${ }^{20}$ showed that 22 of $25(88 \%)$ patients had shoulder pain, but that the average pain score was low $(2.3 \pm 1.3)$.

Kuntz and Weymuller ${ }^{21}$ reported that the modified radical neck dissection group of patients reported greater shoulder disability at 6 months compared with the selective neck dissections group, but at 12 months there was no difference between the two groups.

Giordano et al. ${ }^{22}$ analysed shoulder function after selective and superselective neck dissections, and the subjective test showed no significant differences between the two groups even when sublevel IIB is spared.

The findings of Cheng et al. ${ }^{23}$ in their prospective study with subjective evaluation of shoulder pain and objective evaluation of shoulder muscle strength suggested that patients who underwent selective neck dissection had the least damage to spinal accessory nerve function and the least shoulder disability after neck dissection.

Cappiello et al. ${ }^{24}$ compare the results of clinical and electrophysiological investigations of shoulder function in patients affected by head and neck carcinoma, and a high number of abnormalities was found on electrophysiologi- cal testing, only a limited number of patients, mostly in group B (received a selective neck dissection involving clearance of levels II-V), displayed shoulder function disability affecting daily activities.

In a study by Remmler et al. ${ }^{25}$ modified nerve sparing dissections were followed on the average by a significant, but temporary and reversible phase of shoulder dysfunction. By comparison, radical neck dissection is followed by profound and permanent trapezius muscle weakness and denervation ${ }^{25}$.

Birinci et al. ${ }^{26}$ carried out a prospective, double-blind clinical trial where shoulder function deterioration was significantly less for patients with insignificant intraoperative neuromonitoring changes than in patients with significant intraoperative neuromonitoring changes $(\mathrm{P}<0.05)$.

Chepeha et al. ${ }^{27}$ concluded that patients receiving modified radical neck dissection had significantly worse shoulder function than patients with selective neck dissection $(\mathrm{p}=0.0007)$.

Van Wilgen et al. ${ }^{28}$ reported that after modified radical neck dissection $33.3 \%$ of patients experienced shoulder complaints; after postero-lateral neck dissection $66.7 \%$ and after supraomohyoid neck dissection $20 \%$ of the patients experienced shoulder complaints. Wilgen et al. ${ }^{28}$ indicated that the type of neck dissection was significantly $(\mathrm{P}<0.001)$ related to shoulder complaints.

Selcuk et al. ${ }^{29}$ showed that in patients who underwent anterolateral neck dissection, the goniometric results were better than with the functional neck dissection.

Macaluso et al. ${ }^{30}$ reported that early detection of spinal accessory nerve injuries can be improved through EMG testing.

According to Svenberg et al. ${ }^{31}$, an important landmark in the neck is to detect the branches from cervical plexus to potentially provide the surgeon with important intraoperative nerve identification and monitoring following surgical injury to the SAN.

Our study indicates that there may be functional disability associated with any type of neck dissection in which the spinal accessory is dissected and placed in some degree of traction. The finding of significantly lower risk of functional disability in modified neck dissections, and confirmation that the modified neck dissection is as effective as the radical neck dissection for controlling neck disease, extends the indications for modified or selective neck dissections as a more logical approach to surgical treatment 
of cervical neck disease. If there is no functional advantage, all other arguments for modified neck dissections become inappropriate.

We proposed that adhesive capsulitis is a principal component of XI nerve syndrome that can significantly compound the morbidity of a neck dissection even when the accessory nerve recovers ${ }^{32}$. The subsequent development of adhesive capsulitis in our patients disappeared after 2 months postoperatively.

The results of this study show that, on average, neck dissection patients with the spinal accessory nerve preserved have less pain in their shoulders, less functional disability and stronger results on physical examination than those with the spinal accessory nerve sacrificed without any difference in local control and survival. This is of importance because any inadvertent injury to the spinal accessory nerve during surgical procedures is a cause of significant morbidity with medicolegal repercussions. The findings in this work are consistent to some previous studies regarding te spinal accessory nerve preservation ${ }^{139}$. This study has the advantage that it originated from existing operative findings rather than cadaver dissections and, as a result, incorporated functional information and postoperative significance of damage to selected muscle functions.

\section{Conclusions}

We can validate that the spinal accessory nerve injury is potentially preventable in most cases of neck surgery. Surface anatomical landmarks are not always a reliable guide to the position and course of the nerve in the posterior triangle. Within modified neck dissections, identification of spinal accessory nerve over established landmarks is unconditionally reliant on the exact preoperative mapping of the nerve with imaging diagnostics, but the sophisticated further eleventh nerve dissection and preservation depends on the inclusive surgical knowledge. Modified neck dissection has similar regional control rates to more comprehensive operations in appropriately selected patients and significantly reduces the risk of functional disability.

\section{Acknowledgements}

The presented study has been carried with interdisciplinary assistance of all authors.

\section{References}

1 Chen DT, Chen PR, Wen IS, et al. Surgical anatomy of the spinal accessory nerve: is the great auricular point reliable? J Otolaryngol Head Neck Surg 2009;38:337-9.

2 Durazzo MD, Furlan JC, Teixeira GV, et al. Anatomic landmarks for localization of the spinal accessory nerve. Clin Anat 2009;22:471-5.

3 Lloyd S. Accessory nerve: anatomy and surgical identification. J Laryngol Otol 2007;121:1118-25.
4 Shah J, Patel S. Head and Neck surgery and oncology. III ed. Edinburgh, London, New York, Toronto: Mosby; 2003. p. 353-394.

5 Saman M, Etebari P, Pakdaman MN, et al. Anatomic relationship between the spinal accessory nerve and the jugular vein: a cadaveric study. Surg Radiol Anat 2011;33:175-9.

6 Tubbs RS, Stetler W, Louis RG Jr, et al. Surgical challenges associated with the morphology of the spinal accessory nerve in the posterior cervical triangle: functional or structural? J Neurosurg Spine 2010;12:22-4.

7 Veyseller B, Aksoy F, Ozturan O, et al. Open functional neck dissection: surgical efficacy and electrophysiologic status of the neck and accessory nerve. J Otolaryngol Head Neck Surg 2010;39:403-9.

8 Aravind R, Kathiresan N. Radical neck dissection: preserving the distal spinal accessory nerve based on its cervical plexus contribution. J Surg Oncol 2008;98:200-1.

9 Popovski V. Massive deep lobe parotid neoplasms and parapharyngeal space-occupying lesions: contemporary diagnostics and surgical approaches. Sec Biol Med Sci MASA 2007;28:113-27.

10 Thawley SE, Panje WR, Batsakis JG. Comprehensive Management of Head and Neck Tumors. Vol. II. Philadelphia: W.B. Saunders Company; 1999. p.1147-1172.

11 Boström D, Dahlin LB. Iatrogenic injury to the accessory nerve. Scand J Plast Reconstr Surg Hand Surg 2007;41:82-7.

12 Hashimoto Y, Otsuki N, Morimoto K, et al. Four cases of spinal accessory nerve passing through the fenestrated internal jugular vein. Surg Radiol Anat 2012;34:373-5.

13 Lima LP, Amar A, Lehn CN. Spinal accessory nerve neuropathy following neck dissection. Braz J Otorhinolaryngol 2011;77:259-62.

14 Salgarelli AC, Landini B, Bellini P, et al. A simple method of identifying the spinal accessory nerve in modified radical neck dissection: anatomic study and clinical implications for resident training. Oral Maxillofac Surg 2009;13:69-72.

15 Cummings CW, Fredrickson JM. Otolaryngology - Head and neck surgery. II ed. Year Book, St. Louis-BaltimoreBoston: Mosby; 1993. Vol. II, p. 1043-1078.

16 Skinner SA. Neurophysiologic monitoring of the spinal accessory nerve, hypoglossal nerve, and the spino-medullary region. J Clin Neurophysiol 2011;28:587-98.

17 Lee SH, Lee JK, Jin SM, et al. Anatomical variations of the spinal accessory nerve and its relevance to level IIb lymph nodes. Otolaryngol Head Neck Surg 2009;141:639-44.

18 Watkins JP, Williams GB, Mascioli AA, et al. Shoulder function in patients undergoing selective neck dissection with or without radiation and chemotherapy. Head Neck 2011;33:615-9.

19 Patten C, Hillel AD. The $11^{\text {th }}$ nerve syndrome. Accessory nerve palsy or adhesive capsulitis? Arch Otolaryngol Head Neck Surg 1993;119:215-20.

20 Lee $\mathrm{CH}$, Huang NC, Chen HC, et al. Minimizing shoulder syndrome with intra-operative spinal accessory nerve monitoring for neck dissection. Acta Otorhinolaryngol Ital 2013; 33:93-6.

21 Kuntz AL, Weymuller EA, Jr. Impact of neck dissection on quality of life. Laryngoscope 1999;109:1334-8. 
22 Giordano L, Sarandria D, Fabiano B, et al. Shoulder function after selective and superselective neck dissections: clinical and functional outcomes. Acta Otorhinolaryngol Ital 2012;32:376-9.

23 Cheng PT, Hao SP, Lin YH, et al. Objective comparison of shoulder dysfunction after three neck dissection techniques. Ann Otol Rhinol Laryngol 2000;109:761-6.

24 Cappiello J, Piazza C, Giudice M, et al. Shoulder disability after different selective neck dissections (levels II-IV versus levels $I I-V)$ : a comparative study. Laryngoscope 2005;115:259-63.

25 Remmler D, Byers R, Scheetz J, et al. A prospective study of shoulder disability resulting from radical and modified neck dissections. Head Neck Surg 1986;8:280-6.

26 Birinci Y, Genc A, Ecevit MC, et al. Spinal accessory nerve monitoring and clinical outcome results of nervesparing neck dissections. Otolaryngol Head Neck Surg 2014;151:253-9.

27 Chepeha DB, Taylor RJ, Chepeha JC, et al. Functional assess- ment using Constant's Shoulder Scale after modified radical and selective neck dissection. Head Neck 2002;24:432-6.

28 van Wilgen CP, Dijkstra PU, van der Laan BF, et al. Shoulder complaints after nerve sparing neck dissections. Int J Oral Maxillofac Surg 2004;33:253-7.

29 Selcuk A, Selcuk B, Bahar S, et al. Shoulder function in various types of neck dissection. Role of spinal accessory nerve and cervical plexus preservation. Tumori 2008;94:36-9.

30 Macaluso S, Ross DC, Doherty TJ, et al. Spinal accessory nerve injury: A potentially missed cause of a painful, droopy shoulder. J Back Musculoskelet Rehabil 2016;29:899-904.

31 Svenberg Lind C, Lundberg B, Hammarstedt Nordenvall L, et al. Quantification of trapezius muscle innervation during neck dissections: cervical plexus versus the spinal accessory nerve. Ann Otol Rhinol Laryngol 2015;124:881-5.

32 Patten $\mathrm{C}$, Hillel AD. The $11^{\text {th }}$ nerve syndrome. Accessory nerve palsy or adhesive capsulitis? Arch Otolaryngol Head Neck Surg 1993;119:215-20.

Received: September 23, 2016 - Accepted: November 17, 2016

Address for correspondence: Aleksandar Stamatoski, Clinic for Maxillofacial Surgery, St Cyril and Methodius University, Skopje, R. Macedonia. Tel. +389 2 3163371; +38977 5566 62. Fax +389 2 3238464. E-mail: alexandar.stamatoski5999@gmail.com 